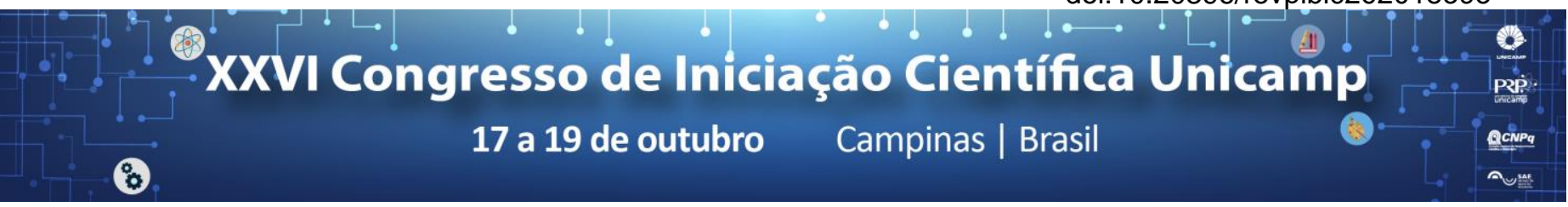

\title{
Eficiência da amostragem em grade para caracterização da fertilidade do solo e prescrição de fertilizantes.
}

\section{Euline Silva Nogueira*, Igor Queiroz Moraes Valente, Lucas Rios do Amaral.}

\section{Resumo}

Este trabalho teve como objetivo avaliar qual tipo de amostragem em grade, densidade e tratamento de dados que melhor representa a fertilidade do solo e possibilita a prescrição de fertilizantes para aplicações em doses variadas. A interpolação de dados precedida por amostragem de solo por célula gerou os menores erros de estimativa de aplicação de fertilizantes. Logo, esse procedimento poderá ser mais eficiente para gerar mapas de prescrição. No entanto, mais estudos precisam ser conduzidos para validar esse método.

\section{Palavras-chave:}

Agricultura de precisão, Fertilidade do solo, Taxas variáveis.

\section{Introdução}

A Agricultura de Precisão propõe a amostragem sistemática de solos numa determinada área através da amostragem em grade. Ela pode ser subdividida em amostragem pontual e amostragem em célula. $\mathrm{Na}$ amostragem pontual é gerada uma malha virtual de pontos a serem coletados. A superfície do mapa é criada usando-se interpolação. Para a amostragem por célula, a área analisada é subdividida em áreas menores, chamadas de células, cada uma delas é amostrada e representada individualmente. Dessa forma não é necessário o uso de interpolação. Contudo, muitas empresas prestadoras de serviço têm amostrado o solo por célula, mas com posterior interpolação dos dados. Tal prática gera controvérsias entre os utilizadores de cada uma das metodologias e o agricultor não tem informação sobre qual utilizar.

O objetivo deste trabalho foi avaliar qual tipo de amostragem em grade e tratamento de dados melhor representa a fertilidade do solo e, consequentemente, a prescrição de fertilizantes em doses variadas, quando da amostragem de solo em diferentes densidades. A partir de duas formas de amostragem (pontual e célula) em diferentes densidades em área de 97 ha cultivada com cana, geramos mapas de prescrição para potássio $(K)$ e fósforo $(P)$ e avaliamos seu desempenho por meio de pontos de validação.

\section{Resultados e Discussão}

Seria esperado correlação dos teores de $\mathrm{P}$ e K no solo quando se estima valores por interpolação para amostras de validação coletadas no mesmo campo. Porém, notamos baixa correlação, mesmo quando utilizada a amostragem mais densa (Tabela 1).

As doses de fertilizantes seguiram 0 mesmo comportamento da correlação, sendo que a amostragem em célula seguida por interpolação dos dados gerou os menores erros, principalmente para o $\mathrm{P}$ (Figura 1). Isto provavelmente deve-se à suavização dos teores no solo provocada por este tipo de amostragem.

Porém, teoricamente a interpolação de dados de amostragem que representam uma área (célula) não poderia ser realizada por krigagem ordinária. Assim, são necessários mais estudos para comprovar se essa tendência se mantém, assim como investigar a forma adequada de interpolar esses dados.
Tabela 1. Correlação de Spearman e seu valor de significância ( $p$ valor) entre o teor real e estimado de $\mathrm{P}$ e $\mathrm{K}$.

\begin{tabular}{|c|c|c|c|c|c|}
\cline { 3 - 6 } \multicolumn{2}{c|}{} & \multicolumn{2}{c|}{ Potássio } & \multicolumn{2}{c|}{ Fósforo } \\
\cline { 3 - 6 } \multicolumn{1}{c|}{} & & $\mathrm{r}$ & $p$ valor & $\mathrm{r}$ & $p$ valor \\
\hline 1 ha & $\mathrm{A}$ & 0,428 & 0,042 & 0,406 & 0,061 \\
\hline \multirow{4}{*}{ h ha } & $\mathrm{A}$ & 0,437 & 0,037 & 0,38 & 0,081 \\
\cline { 2 - 6 } & $\mathrm{Bl}$ & 0,527 & 0,01 & 0,357 & 0,103 \\
\cline { 2 - 6 } & $\mathrm{B}$ & 0,385 & 0,069 & 0,415 & 0,061 \\
\hline \multirow{4}{*}{ 4 ha } & $\mathrm{A}$ & 0,556 & 0,006 & 0,526 & 0,012 \\
\cline { 2 - 6 } & $\mathrm{Bl}$ & 0,567 & 0,005 & 0,355 & 0,105 \\
\cline { 2 - 6 } & $\mathrm{BCl}$ & 0,651 & 0,001 & 0,578 & 0,005 \\
\cline { 2 - 6 } & $\mathrm{B}$ & 0,412 & 0,051 & 0,348 & 0,112 \\
\cline { 2 - 6 } & $\mathrm{BC}$ & 0,419 & 0,046 & 0,615 & 0,005 \\
\hline
\end{tabular}

Legenda: A - Amostragem pontual; B - Amostragem em célula; BC Amostragem em célula centralizada; $\mathrm{BI}$ - Amostragem em célula com interpolação; $\mathrm{BCl}$ - Amostragem em célula centralizada com interpolação.

Figura1. RMSE das doses de fertilizantes para as amostras de validação e os teores estimados conforme o método de amostragem e de análise dos dados.

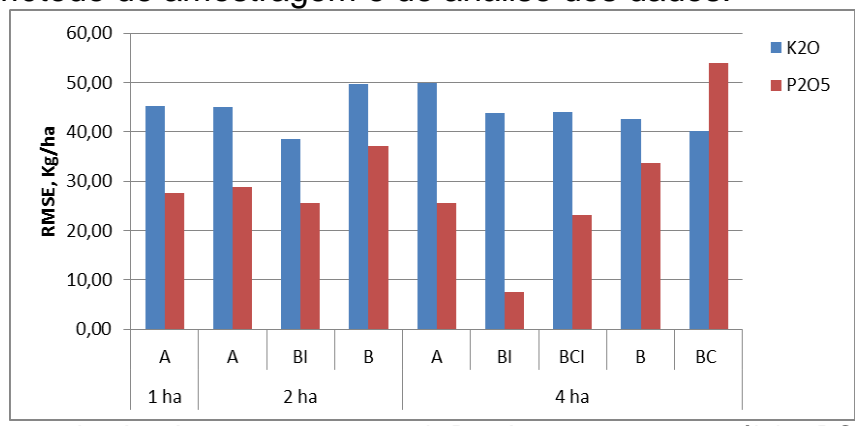

Legenda: A - Amostragem pontual; B - Amostragem em célula; BC Amostragem em célula centralizada; BI - Amostragem em célula com interpolação; $\mathrm{BCl}$ - Amostragem em célula centralizada com interpolação.

\section{Conclusões}

A interpolação de dados precedida por amostragem de solo por célula gerou os menores erros de estimativa de aplicação de fertilizantes. Logo, esse procedimento poderá ser mais eficiente para gerar mapas de prescrição. No entanto, mais estudos precisam ser conduzidos para validar esse método.

Agradecimentos

Ao Pibic/Unicam; Julyane Vieira Fontenelli; Fundação de Amparo à Pesquisa do Estado de São Paulo (FAPESP) e à Ipiranga Agroindustrial S/A. 